\title{
GETTING ON YOUR NERVES: OVER-INVESTIGATION, REFERRAL AND TREATMENT OF BELL'S PALSY
}

\author{
Rosalind Gregory, Isuru Induruwa, Negin Holland, Ravi Thakar, Dorinda Chandrabose, Kayvan Khadjooi \\ Department of Stroke Medicine, Addenbrooke's Hospital, Cambridge, United Kingdom
}

\section{Introduction}

Bell's Palsy (BP), an idiopathic paralysis of cranial nerve VII, results in facial weakness \& dysarthria. It has an annual incidence of $38 / 100000$ people in the UK ${ }^{1}$. It is pathologically distinct from acute stroke and requires differentiation through careful history and neurological examination.

\section{Methods}

We retrospectively studied electronic medical records of all patients with a discharge diagnosis of BP from October 2014 to October 2017 at Cambridge University Hospital, a large tertiary centre with ENT, stroke and neurology services in Cambridge, UK.

Exclusion criteria: age $<18$ years old, pre-existing BP diagnosis and elective admission for aesthetic surgery. None of the patients included had had any recent head injury or trauma.

\section{Results}

Out of 46 patients, 13 presented to the emergency department (ED) after initial assessment by GP, 8 of whom were referred as a possible stroke. Only 1 patient was discharged directly from ED and the average hospital length of stay (LOS) was nearly 2 days, during which each patient was assessed by 2 to 3 clinicians. Uncertainty in diagnosing BP was evident in both ED and medical teams, many failing to notice or consider 'progression of symptoms' in the history, in order to differentiate BP from stroke. Furthermore, many patients had had symptoms on average for 3 days prior admission, which was not always recognised at initial clerking. Therefore, $83 \%$ of patients underwent neuroimaging and $59 \%$ were referred to stroke/neurology for specialist opinion (Figures $1 \& 3$ ). From initial clerking, only 9 patients received steroids until further investigations or specialist review was completed. 31/46 patients received no treatment (steroids) after initial clerking, with all being referred for further imaging, medical or neurology specialist opinion prior to treatment (Figure 2).

\begin{tabular}{|cc|}
\hline Total Screened (n) & $\mathbf{1 1 8}$ \\
\hline Excluded $(\mathbf{n})$ & 72 \\
\hline Included (n) & 46 \\
\hline Mean age (SD) & $59(18.6)$ \\
\hline Male (\%) & 48 \\
\hline Primary care referrals & $13(28.3 \%)$ \\
\hline LOS 1 day & 22 \\
\hline LOS 2 day & 9 \\
\hline LOS 3 day & 11 \\
\hline LOS 4 day & 1 \\
\hline Average LOS (days) & 1.75 \\
\hline $\begin{array}{c}\text { Average no. of clinicians } \\
\text { reviewing each patient }\end{array}$ & 2.85 \\
\hline
\end{tabular}

Table 1. Basic demographics of the population and information regarding the admission and in-patient stay of the patients included in the study.

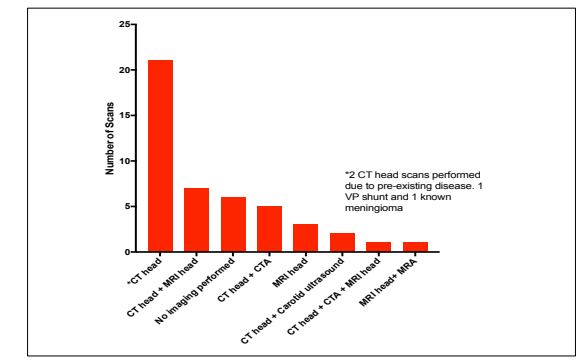

Figure 1. Number of different imaging modalities undertaken in 46 patients.

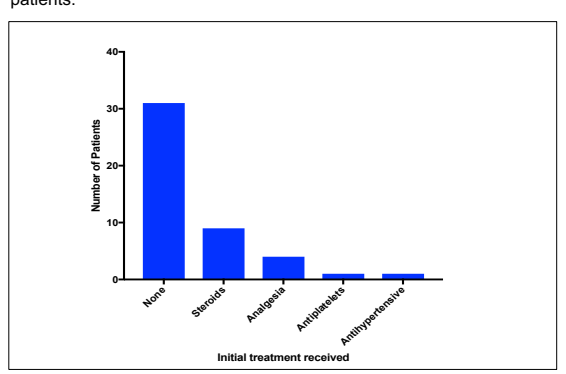

Figure 2. 31 patients were referred for specialist review or imaging prior to commencing steroid treatment.

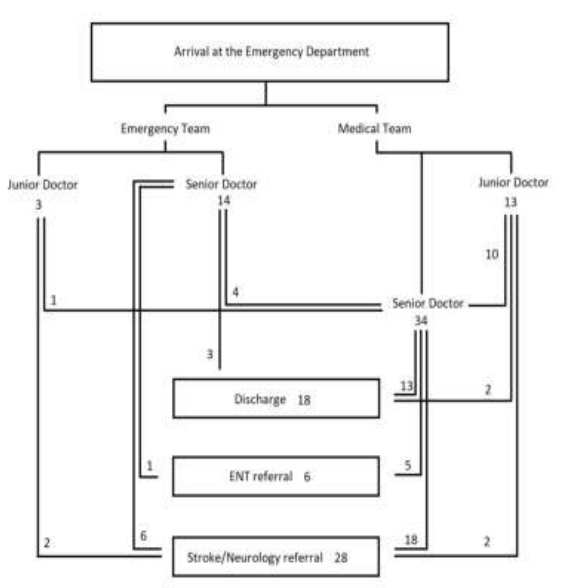

Figure 3. Indecision amongst clerking doctors leading to
multiple referrals between $E D$ and medical teams, as well as to troke and neurology specialist teams for BP.

\section{$\operatorname{ESOCO} 200$}

\section{Conclusion}

BP should ideally be managed in primary care and self-referring patients should be discharged from ED. Our study shows a lack of confidence (and possibly awareness) amongst clinicians, including GPs and senior medical staff, in diagnosing BP. Continuous education amongst non-specialists is required to avoid inappropriate referrals in both primary and secondary care which can lead to considerable patient stress and waste of medical resources through bed occupancy, over-investigation and inappropriate treatment. 